\title{
Formulation Development and Evaluation of a Gastroretentive in situ oral gel of Cefuroxime Axetil
}

\author{
Divyesh Harshadkumar Shastri, Hitesh Dhirubhai Dodiya, Pragna Shelat, Alkesh Kishanlal Bhanupriy \\ Department of Pharmaceutics, K. B. Institute of Pharmaceutical Education \& Research, Gh-6, sector-23, Kadi Campus, Gandhinagar, Gujarat, INDIA-382023.
}

\begin{abstract}
Objective: To develop a gastroretentive in situ oral gel to improve the bioavailability of the cephalosporin antibiotic drug, Cefuroxime Axetil. Methodology: Sodium alginate and pectin were the ionic dependent gel forming polymer. Calcium chloride was used as complexing agent to increase cross linking along with sodium citrate. Mucoadhesion was enhanced with the help of polymer HPMC K4M. Two factors and three levels factorial design was used for the optimization of formulation using design expert software version 7.1.6. The In situ gel system was evaluated for the content uniformity, $\mathrm{pH}$, gelling capacity, viscosity of gel, invitro drug release and mucoadhesion study. Results and Discussion: Optimized formula showed more than 24\% Drug release after 1 hour and prolonged release up to 12 hour, Viscosity of gel formed was 6423.9 cps and $3.668 \mathrm{~N} / \mathrm{cm}^{2}$. The results revealed that as the concentration of Sodium alginate was directly proportional to mucoadhesion, inversely proportional to drug release while concentration of pectin directly pro-
\end{abstract}

portional to drug release. Conclusion: The study point to the potential of in situ oral gel in terms of ease of administration, better patient compliance and prolonged gastro-retention.

Key words: Gastro-retentive drug delivery system, Mucoadhesive Oral Insitu gel, Cefuroxime Axetil.

Correspondence :

Dr. Divyesh Harshadkumar Shastri,

Assistant Professor, Department of Pharmaceutics, K. B. Institute of Pharmaceutical Education \& Research, Gh-6, sector-2s3, Kadi Campus, Gandhinagar, Gujarat, INDIA-382023

Cell: +919426420259

E-mail: divyeshshastri@gmail.com

DOI: 10.5530/jyp.2016.4.6

\section{INTRODUCTION}

Cefuroxime is the first commercially available second generation, semi-synthetic cephalosporin obtained from the 7-cehalosporanic acid nucleus of cephalosporin C. In humans, gastrointestinal absorption of cefuroxime is negligible due to its poor aqueous solubility and instability, whereas the acetoxyethyl ester of cefuroxime (Cefuroxime Axetil), an oral prodrug shows a bioavailability of 30 to $40 \%$ when taken on fasting and 50 to $60 \%$ when taken after food. Cefuroxime Axetil is used in the treatment of common community acquired infections because of its in-vitro antibacterial activity against several gram-positive and gramnegative organisms. ${ }^{1}$

Gastro-retentive dosage forms (GRDFs) are designed to be retained in the stomach for a prolonged time and release their active ingredients and thereby enable sustained and prolonged input of the drug to the upper part of the gastrointestinal (GI) tract. ${ }^{2-6}$

The gastro-retentive drug delivery systems can be retained in the stomach and contribute in improving the oral sustained delivery of drugs that have an absorption window in a particular region of the gastrointestinal tract. $^{7-9}$ These systems help in continuously releasing the drug before it reaches the absorption window, thus ensuring optimal bioavailability. ${ }^{10-12}$ Gastro-retention is achieved by Expandable systems, Bio/Mucoadhesive systems, floating drug delivery systems and Combination of floating, mucoadhesion and swellable system. ${ }^{13-15}$

The in situ gelling system is a type of mucoadhesive drug delivery system principally capable of releasing drug molecule in a sustained manner affording relatively constant plasma profile. These formulations are liquid at room temperature but undergo gelation when in contact with body fluids or change in $\mathrm{pH}$. These have a characteristic property of temperature dependent, $\mathrm{pH}$ dependent and cation induced gelation. In situ gelling formulations are widely applicable for ocular, nasal, vaginal and oral therapy. It has several advantages as a dosage form for oral administration like maximum intimate contact of the drug at the absorp- tion site, influenced rate of absorption, ease of preparation, homogeneity of drug distribution compared to other conventional suspensions. Thus in the present study an attempt was made to prepare a formulation of Cefuroxime Axetil as in situ gel forming drug delivery system for oral delivery using Pectin and Sodium alginate as gel forming agents. ${ }^{16-20}$

Pectins are a family of polysaccharides in which the polymer backbone mainly comprises- $(1 \rightarrow 4)$-d-galacturonic acid residues. Low methoxy pectins (degree of esterification $<50 \%$ ) readily form gels in aqueous solution in the presence of free calcium ions, which cross-link the galacturonic acid chains as 'egg-box' model.

Aqueous solutions of sodium alginateundergo gelation in presence of di- or tri-valent metal ions by a co-operative process involving consecutive glucuronic residues in the alpha-L-glucuronic acid blocks of the alginatechain. Reproducible gelation of these polysaccharides is ensured by including a source of $\mathrm{Ca}^{+2}$ ions in the formulation, but gelation is delayed until the administered solution reaches the stomach by complexing the calcium with sodium citrate. Here the acidic environment causes breakdown of the complex, releasing free $\mathrm{Ca}^{+2}$ ions and causing instantaneous gelation. $^{21-25}$

The goal of the present work is to develophydro dynamically balanced system or floating drug delivery system for Cefuroxime Axetil, which increases the gastric residence time, decreases the diffusion resistance and allow more of antibiotic to penetrate through the gastric mucus layer and act locally at the infectious site. 5 to $60 \%$ when taken after food 4-7. The low bioavailability and short biological half life (1.5 hours) of Cefuroxime Axetil following oral administration favours development of a gastro-retentive formulation.

\section{MATERIAL AND METHODS}

\section{Materials}

Cefuroxime Axetil was obtained from Comed Pharmaceuticals ltd., Baroda, GJ, IND. Sodium Alginate and Eosine yellow (Loba chemie Pvt. 
Ltd., Mumbai, IND), Low Methoxy grade Pectin (C.P Kelco, Mumbai, IND), HPMC K4M (Colorcon, Goa, IND) were used as received. Sodium Citrate (Merck India Ltd., Mumbai, IND), Calcium Chloride (Suvidhi lab., Baroda, GJ, IND), Sodium Benzoate (Burguyne Urbidges \& Co., Mumbai, IND), Sodium Saccharin (Bombay Tablets ltd., GJ, IND) were purchased.

\section{Preparation of sol and suspension}

Weighed amount of sodium alginate and pectin were added to the $40 \mathrm{~mL}$ ultrapure water containing sodium citrate $(0.25 \% \mathrm{w} / \mathrm{v})$ and calcium chloride $(0.075 \% \mathrm{w} / \mathrm{v})$ and heated up to $60^{\circ} \mathrm{C}$ while stirring. After cooling to $40^{\circ} \mathrm{C}$, HPMC $\mathrm{K} 4 \mathrm{M}$ was dissolved with constant stirring. Cefuroxime Axetil (3gm) was added and dispersion was formed. To this suspension appropriate quantity of sodium saccharin, preservative sodium benzoate and coloring agent eosine yellow were added and volume made up to $60 \mathrm{~mL}$ with purified water containing sodium citrate and calcium chloride. The prepared suspension was added to $0.1 \mathrm{~N}$ Hydrochloric acid to form gel.

\section{Evaluation of suspension \\ Fourier transform infrared spectroscopy (FT-IR)}

FTIR study of physical mixture of drug and polymer was carried out to detect for possible drug excipient interaction if any.

\section{$\mathrm{pH}$ measurement}

All the formulations were tested for $\mathrm{pH}$ using digital $\mathrm{pH}$ meter. The measurements were carried out in triplicate and the average value was calculated as shown in Table 2.

\section{Drug content uniformity study ${ }^{26}$}

Drug content of Cefuroxime Axetil was determined by dissolving $5 \mathrm{~mL}$ of suspension in $50 \mathrm{~mL}$ of methanol. The solutions were filtered through whatman filter paper and diluted about 400 times and analyzed for the drug content by UV spectrophotometer at $277 \mathrm{~nm}^{26}$

\section{Viscosity of suspension ${ }^{27}$}

The viscosity measurement of each formulation was determined using Brookfield viscometer DV-II+ Pro LV model. The selected formulations were poured into the sample adaptor of the viscometer and viscosity was measured at $25^{\circ} \mathrm{C}$. The measurements were carried out using spindle S-62 at the speed of 50 RPM and 100 RPM respectively and the viscosity was measured at $10 \mathrm{~min}$ after the rotation of the spindle. The viscosity measurements were made in triplicate using fresh samples each time..$^{27}$

\section{Evaluation of In-situ Gel}

\section{In-vitro gelling capacity study ${ }^{28}$}

In vitro gelling capacity was determined by visual method. Prepared formulations was measured by placing $5 \mathrm{~mL}$ of the $0.1 \mathrm{~N} \mathrm{HCl}(\mathrm{pH} 1.2)$ in a $15 \mathrm{~mL}$ borosilicate glass test tube and maintained at $37 \pm 1^{\circ} \mathrm{C}$ temperature. One $\mathrm{mL}$ of colored formulation was added with the help of pipette. The formulation was transferred in such a way that places the pipette at surface of fluid in test tube and formulation was slowly released from the pipette. As the solution comes in contact with gelation solution, it was immediately converted into stiff gel like structure. The gelling capacity of solution was evaluated on the basis of stiffness of formed gel and time period for which the formed gel remains as such. The in vitro gelling capacity was graded in two categories on the basis of gelation time and time period for which the formed gel remains. ${ }^{28}$

\section{Viscosity measurement of In-situ formed gel ${ }^{29}$}

The viscosity measurement of formulation, after gelling in $0.1 \mathrm{~N}$ Hydrochloride solution was determined using Brookfield viscometer DV-II+ Pro LV model. The selected formulations were poured into the sample adaptor of the viscometer and viscosity was measured at $37^{\circ} \mathrm{C}$. The measurements were carried out using spindle S-63 and S-64 at the speed of 4 RPM and 2.5 RPM respectively and the viscosity was measured at $10 \mathrm{~min}$ after the rotation of the spindle. The viscosity measurements were made in triplicate using fresh samples each time. ${ }^{29}$

\section{Mucoadhesion study ${ }^{30}$}

Mucoadhesion study was carried out using modified mucoadhesion apparatus. There was two glass slides, bottom slide was fixed with wooden base while upper slide was attached to nylon thread, and the other end of nylon thread was attached to plastic bowl. Here the weight of glass slide and plastic bowl was equal. Rate stomach mucosa was fixed on both glass slides using gum. $1 \mathrm{gm}$ of gel was placed between two slide and put $1 \mathrm{~kg}$ weight for removal of air for 5 minute. Water was continuously added to plastic bowl till the two slides were just detached. Measure the quantity of water required and mucoadhesive strength was calculated. ${ }^{30}$

The protocol of the experiment was approved by Institutional Animal Ethical Committee as per the guidance of the Committee for the Purpose of Control and Supervision of Experiments on Animals (Reg. No. 238/ CPCSEA), Ministry of Social Justice and Empowerment, Government of India (19/2011 dated on $19^{\text {th }}$ December, 2011 Form No. KBIPER/299).

\section{In-vitro drug release study ${ }^{31}$}

The in-vitro release studies of Cefuroxime Axetil from the In-situ gel formulation were studied using dissolution testing apparatus USP II. The dissolution medium was $900 \mathrm{~mL}$ freshly prepared 0.1 N Hydrochloric acid ( $\mathrm{pH}$ 1.2). $5 \mathrm{~mL}$ of formulation added to dissolution basket. The paddle speed was 50 RPM. Aliquots, each of $5 \mathrm{~mL}$ volume were withdrawn at 60 minute interval and replaced by an equal volume of $0.1 \mathrm{~N}$ Hydrochloric acid to maintain the sink condition. The aliquots were diluted with dissolution medium and analyzed by UV spectrophotometer at $280 \mathrm{~nm} .^{31}$

\section{Optimization using Factorial design for optimizing the In-situ oral gel ${ }^{32}$}

The use of trial and error technique for the development of a new pharmaceutical formulation leads to a satisfactory formulation rather than an optimal one. The optimization techniques, on the basis of a few experiments and statistical analysis of the results can provide an efficient and economical method for the prediction of the optimal composition. $3^{2}$ Full Factorial Design was employed for the preparation of the In-situ oral gel possessing optimized characteristics. The results were subjected to multiple regression analysis that led to equations describing the effect of independent variables on the selected responses. To study all the possible combinations of all factors at all levels, a two-factor, three-level full factorial design was constructed and conducted in a fully randomized order. The dependent variables measured were Mucoadhesive strength, Viscosity of gel and Cumulative Percentage drug release at $1 \mathrm{~h}$ and at $10 \mathrm{~h}$ in $0.1 \mathrm{~N} \mathrm{HCl}(\mathrm{pH} 1.2) .^{32}$

Two independent factors, the concentration of Sodium Alginate $\left(\mathrm{X}_{1}\right)$ and the concentration of Pectin $\left(\mathrm{X}_{2}\right)$ were set at three different levels. High and low levels of each factor were coded as +1 and -1 , respectively and the mean value as zero. The range of a factor must be chosen in order to adequately measure its effects on the response variables. The range of each factor was chosen from the preliminary studies. This design was selected as it provides sufficient degrees of freedom to resolve the main effects as well as the factor interactions. Stepwise regression analysis 
was used to find out the control factors that significantly affect response variables.

\section{Water uptake study ${ }^{33}$}

A simple method was adopted to determine the water uptake by the gel. The in situ gel formed in $0.1 \mathrm{~N}$ Hydrochloric acid was used for this study. From each formulation the gel portion from the $0.1 \mathrm{~N}$ Hydrochloric acid was separated and the excess solution was blotted out with a tissue paper. The initial weight of the gel taken was weighed and to this gel $10 \mathrm{~mL}$ of distilled water was added and after every 30 minutes of the interval water was decanted and the weight of the gel was recorded and the difference in the weight was calculated and reported..$^{33}$

\section{Stability study of optimized batch}

Stability study was performed optimized batch for any physicochemical changes. The formulation was filled in glass bottle and stored at room temperature for period of one month. The formulation was evaluated after the period of one month for in-vitro drug release.

\section{RESULTS AND DISCUSSION}

\section{Preliminary Studies}

FTIR study of physical mixture of drug and polymer indicated that all the excipients chosen were compatible with the drug.

\section{$\mathrm{pH}$ Measurement study}

As shown in Table 2, pH of all formulation was in range of 6.31 to 6.72 . In this range formulation was stable and do not affect drug properties, so there was no need for $\mathrm{pH}$ adjustment.

\section{Content uniformity study}

The percentage drug content of all the formulations was found to be in the range of $89.52 \%$ to $114.22 \%$ (Table 2 ).

\section{Viscosity measurement of suspension}

Result of present study shown in Table 2.Viscosity measurement of all formulations was varies from 84 to $252.75 \mathrm{cps}$. All the formulations were found easily pourable.

\section{Evaluation of In-situ Gel}

Gelation time and residence time present in Table 3. The result of Table 3 showed no significant difference in gelation time of all the formulation as well as residence time of the gel. The gelation time for all the formulation was between 5 to 15 seconds and formed gel lasted for $>12$ hour which was suitable for our study.

\section{Viscosity study}

Result of viscosity measurement present in the Table 3. Viscosity of In-situ formed gel of the all formulations was varies from 3398 to $57564.5 \mathrm{cps}$ according to level of polymer added. There was directly proportional effect of polymer concentration on viscosity, so viscosity of In-situ formed gel of the formulation was taken as one of the dependent parameter for optimization of formulation. ${ }^{34}$

\section{Mucoadhesion study}

Table 3 showed the Result of mucoadhesive strength. The mucoadhesive strength of all formulations was varies from 3.516 to $5.579 \mathrm{~N} / \mathrm{cm}^{2}$. There was directly proportional effect of polymer concentration on mucoadhesive strength, so mucoadhesive strength of the formulation was taken as one of the dependent parameter for optimization of formulation. ${ }^{35,36}$

\section{In-vitro Drug Release Study}

The effect of polymer concentration on in vitro drug release from in situ gel formulations were shown in Figure 1. A significant decrease in the rate of drug release was observed with the increase in polymer concentration and it was attributed to increase in the density of the polymer matrix. The release of drug from these gel formulations were characterized by an initial phase of high release (burst effect). However, as gelation proceeds the remaining drug was released at a slower rate followed by a second phase of moderate release. This biphasic pattern of release is a characteristic feature of matrix diffusion kinetics. As the proportion of Sodium Alginate increased in the gelling systems, a significant decrease in the drug release was observed. As in all cases, the release from batch $\mathrm{A}$ to I followed a biphasic pattern, with initial phase of high release followed by a phase of moderate release. Though the cross-linking of the sodium alginate network and eventually the gelation due to the $\mathrm{Ca}^{+2}$ ions occurs instantaneously, a lag time is still evident before the complete gel formation. This could explain the initial high release of Cefuroxime Axetil, which was soluble at lower $\mathrm{pH}$. Further, the system was formulated in aqueous vehicle, hence the matrix formed before the complete gelation/cross linking would already be in a hydrated state thereby discounting the matrix hydration and water permeation that would normally limit drug release during the initial stages.

\section{Release kinetic study}

Drug release data of all the formulation were fitted into different release kinetic model like Zero-order, First-order, Higuchi, Hixson-Crowell and Korsemeyer-Peppas.Results of release kinetic study are shown in the Table 4.

The best fitted model was selected on the basis of relatively high R-square values. All the formulation have diffusion exponent $(\mathrm{n})$ values between 0.5 to 0.85 which indicates that all the formulations were following nonFickian diffusion (Anomalous diffusion). Batch A followed the release as per Korsemeyer-Peppas model. Drug release from the formulation (batch code B to I) can be best explained by the Higuchi model due to highest R-square value among all the models.

\section{Factorial design}

In-situ oral gel was prepared by ionic cross linking method. Two factors and 3 levels full factorial design was used to optimize the formulation which could sustain the drug release up to $12 \mathrm{~h}$. Amount of Sodium alginate $\left(\mathrm{X}_{1}\right)$ and amount of Pectin $\left(\mathrm{X}_{2}\right)$ were selected as independent

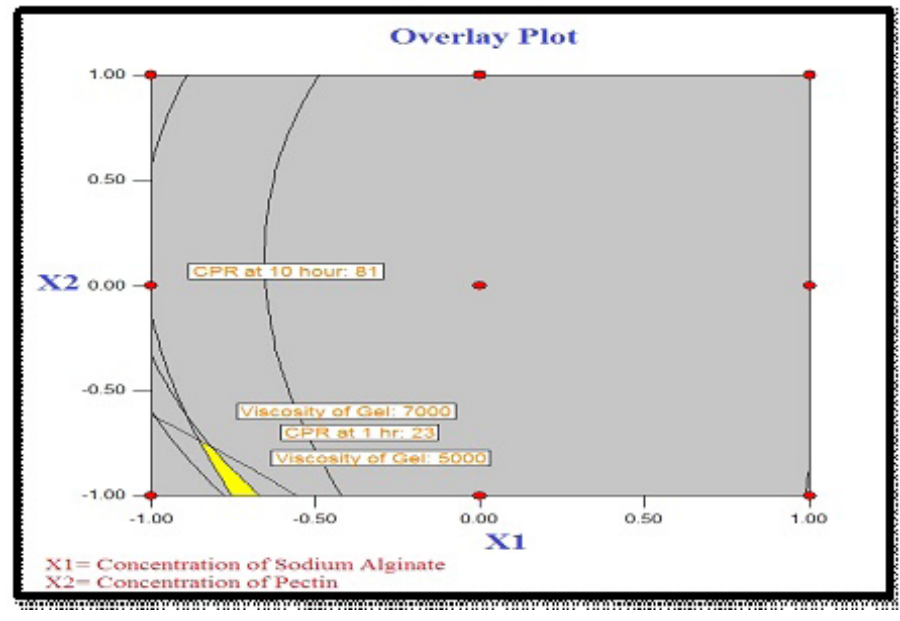

Figure 1: Effect of polymer concentration on in vitro drug release from in situ gel formulations. 


\section{Table 1: Formulation of Batch A to I}

\begin{tabular}{cccccccccc}
\hline \multirow{2}{*}{ Batch code Ingredients } & \multicolumn{10}{c}{ Content (\% w/v) } \\
\cline { 2 - 10 } & A & B & C & D & E & F & G & H & I \\
\hline Cefuroxime Axetil & 5 & 5 & 5 & 5 & 5 & 5 & 5 & 5 & 5 \\
Sodium Alginate & 0.3 & 0.3 & 0.3 & 0.5 & 0.5 & 0.5 & 0.7 & 0.7 & 0.7 \\
Pectin & 0.3 & 0.5 & 0.7 & 0.3 & 0.5 & 0.7 & 0.3 & 0.5 & 0.7 \\
HPMC K4M & 0.5 & 0.5 & 0.5 & 0.5 & 0.5 & 0.5 & 0.5 & 0.5 & 0.5 \\
Sodium Citrate & 0.25 & 0.25 & 0.25 & 0.25 & 0.25 & 0.25 & 0.25 & 0.25 & 0.25 \\
Calcium Chloride & 0.075 & 0.075 & 0.075 & 0.075 & 0.075 & 0.075 & 0.075 & 0.075 & 0.075 \\
Sodium Saccharin & 0.2 & 0.2 & 0.2 & 0.2 & 0.2 & 0.2 & 0.2 & 0.2 & 0.2 \\
Sodium Benzoate & 0.1 & 0.1 & 0.1 & 0.1 & 0.1 & 0.1 & 0.1 & 0.1 & 0.1 \\
Waterq.s. to 60 ml & 100 & 100 & 100 & 100 & 100 & 100 & 100 & 100 & 100 \\
\hline
\end{tabular}

Table 2: Results of different evaluation parameter of suspension formulation

\begin{tabular}{ccccc}
\hline Batch code & pH & \% Content & $\begin{array}{c}\text { Viscosity } \\
\text { (cPs) }\end{array}$ & $\begin{array}{c}\text { Redispersibility/ No } \\
\text { of Strokes }\end{array}$ \\
\hline A & $6.72 \pm 0.01$ & $102.7768 \pm 1.12$ & $* 84 \pm 1.4$ & Fair/ 02 \\
B & $6.54 \pm 0.01$ & $97.98 \pm 1.16$ & $128.3 \pm 3.6$ & Good/ 01 \\
C & $6.51 \pm 0.01$ & $114.22 \pm 1.80$ & $179 \pm 2.1$ & Good/ 01 \\
D & $6.62 \pm 0.01$ & $92.13 \pm 1.77$ & $133.3 \pm 3.8$ & Fair/ 02 \\
E & $6.45 \pm 0.01$ & $89.52 \pm 0.95$ & $140.6 \pm 1.6$ & Fair/ 02 \\
F & $6.31 \pm 0.02$ & $95.12 \pm 0.38$ & $199.5 \pm 1.54$ & Fair/ 02 \\
G & $6.71 \pm 0.01$ & $94.99 \pm 0.67$ & $141.5 \pm 2.68$ & Good/ 01 \\
H & $6.55 \pm 0.03$ & $102.65 \pm 0.81$ & $203.1 \pm 3.82$ & Good/ 01 \\
I & $6.45 \pm 0.02$ & $98.98 \pm 1.02$ & $252.75 \pm 2.6$ & Good/ 01 \\
\hline
\end{tabular}

${ }^{\star}$ Indicated Mean \pm SD, $\mathrm{n}=3$.

Table 3: Results of different evaluation parameter of $I n$ situ gel

\begin{tabular}{cccc}
$\begin{array}{c}\text { Batch } \\
\text { code }\end{array}$ & Gelation time & $\begin{array}{c}\text { Viscosity } \\
(\mathrm{cPs})\end{array}$ & $\begin{array}{c}\text { Mucoadhesive } \\
\text { Strength } \\
\left(\mathrm{N} / \mathrm{cm}^{2}\right)\end{array}$ \\
\hline A & Moderate & $3398 \pm 2.86$ & $\star 3.516 \pm 0.11$ \\
B & Good & $5521 \pm 1.46$ & $3.668 \pm 0.12$ \\
C & Excellent & $9657 \pm 1.99$ & $3.821 \pm 0.11$ \\
D & Moderate & $17876 \pm 2.11$ & $4.127 \pm 0.21$ \\
E & Good & $28859 \pm 1.65$ & $4.204 \pm 0.12$ \\
F & Excellent & $39232 \pm 2.34$ & $4.356 \pm 0.12$ \\
G & Moderate & $31793.5 \pm 2.84$ & $5.121 \pm 0.11$ \\
H & Good & $56900 \pm 3.46$ & $5.350 \pm 0.12$ \\
I & Excellent & $57564.5 \pm 3.66$ & $5.579 \pm 0.21$ \\
\hline
\end{tabular}

Gelation time: Excellent: less than 1 min, Good: 1 to 1.5 min, Moderate: 2 min ${ }^{\star}$ Indicated Mean $+/-$ SD, $n=3$.

variables. The prepared batches were characterized for different parameters. The gelling capacity, water uptake, drug content, viscosity of formulation, and $\mathrm{pH}$ were acceptable for all the batches hence they were not subjected to statistical analysis. The viscosity of the gel $\left(R_{1}\right)$, mucoadhesive strength $\left(R_{2}\right)$, percentage drug release at $1 \mathrm{~h}\left(\mathrm{R}_{3}\right)$ and percentage drug release at $10 \mathrm{~h}$ $\left(R_{4}\right)$ were taken as dependent variables.
Statistical analysis was performed using Design Expert Software (Version 7.1.6, Stat- Ease Inc, Minneapolis, $M N$ ) by taking $\mathrm{X}_{1}$ and $\mathrm{X}_{2}$ as independent variable. $R_{1}, R_{2}, R 3$ and $R 4$ were taken as responses (dependent variable). The values of $X_{1}, X_{2}, R_{1}, R_{2}, R 3$ and $R 4$ are given in Table 5 .

Viscosity $\left(\mathrm{R}_{1}\right)=31215.61+21280.25 \mathrm{X}_{1}+8897.58 \mathrm{X}_{2}+$ 4877.87 $\mathrm{X}_{1} \mathrm{X}_{2}-1183.42 \mathrm{X}_{1}^{\wedge 2}-3839.92 \mathrm{X}_{2}^{\wedge 2}$

Mucoadhesive strength $\left(\mathrm{R}_{2}\right)=4.25+0.84 \mathrm{X}_{1}-0.025 \mathrm{X}_{2}-0.15 \mathrm{X}_{1} \mathrm{X}_{2}+$

$$
0.28 \mathrm{X}_{1}^{2}-0.025 \mathrm{X}_{2}^{2}
$$

$\mathrm{CPR}$ at $1 \mathrm{hr}\left(\mathrm{R}_{3}\right)=13.31-6.66 \mathrm{X}_{1}-1.92 \mathrm{X}_{2}+2.68 \mathrm{X}_{1} \mathrm{X}_{2}-0.90 \mathrm{X}_{1}^{2}+2.88 \mathrm{X}_{2}^{2}$

$\mathrm{CPR}$ at 10 hour $\left(\mathrm{R}_{4}\right)=63.66-25.80 \mathrm{X}_{1}+0.29 \mathrm{X}_{2}+2.66 \mathrm{X}_{1} \mathrm{X}_{2}+1.14 \mathrm{X}_{1}^{2}+5.50 \mathrm{X}_{2}^{2}$

The data were statistically analyzed using ANOVA test and the generated models were used to identify the optimized batch. Model fitting to the data showed that the quadratic model was suitable to explain the responses. Viscosity of the gel was affected by the concentration of sodium alginate and pectin, as the concentration of polymer increased complexation and cross linking increased with calcium ion and hense viscosity of gel also increased. Mucoadhesive strength was affected by the concentration of sodium alginate; sodium alginate is mucoadhesive polymer hense mucoadhesive strength directly proportional to concentration of sodium alginate.

Drug release at first hour was affected by the amount of sodium alginate, as the amount sodium alginate increased, cross linking increased and release of drug from gel matrix decreased at the end of first hour. Drug release at tenth hour was more affected by the amount of sodium alginate and less affected by pectin, as the amount sodium alginate increased, 
Table 4: Results of kinetic model fitting for batches (A to I)

\begin{tabular}{|c|c|c|c|c|c|c|c|}
\hline \multirow{3}{*}{$\begin{array}{l}\text { Batch } \\
\text { Code }\end{array}$} & \multicolumn{7}{|c|}{ R-Square } \\
\hline & \multirow{2}{*}{ Higuchi } & \multirow{2}{*}{$\begin{array}{l}\text { Zero } \\
\text { Order }\end{array}$} & \multicolumn{3}{|c|}{ Korsemeyer-Peppas } & \multirow{2}{*}{$\begin{array}{l}\text { Hixon } \\
\text { Crowell }\end{array}$} & \multirow{2}{*}{$\begin{array}{l}\text { First } \\
\text { Order }\end{array}$} \\
\hline & & & R Square & $\mathrm{n}$ & K & & \\
\hline A & 0.9982 & 0.9943 & 0.9988 & 0.5318 & 0.2854 & 0.994 & 0.9290 \\
\hline B & 0.9984 & 0.9884 & 0.9958 & 0.680 & 0.197 & 0.9884 & 0.9093 \\
\hline $\mathrm{C}$ & 0.9980 & 0.9798 & 0.9941 & 0.710 & 0.200 & 0.98 & 0.9389 \\
\hline D & 0.9969 & 0.9947 & 0.9979 & 0.631 & 0.153 & 0.995 & 0.9271 \\
\hline $\mathbf{E}$ & 0.9983 & 0.9935 & 0.9985 & 0.716 & 0.126 & 0.993 & 0.9097 \\
\hline $\mathbf{F}$ & 0.9986 & 0.9918 & 0.9939 & 0.769 & 0.132 & 0.992 & 0.9579 \\
\hline G & 0.9910 & 0.9994 & 0.9978 & 0.723 & 0.077 & 0.999 & 0.9612 \\
\hline $\mathbf{H}$ & 0.9898 & 0.9997 & 0.9972 & 0.692 & 0.073 & 0.999 & 0.949 \\
\hline I & 0.9908 & 0.9993 & 0.9989 & 0.761 & 0.076 & 0.999 & 0.9295 \\
\hline
\end{tabular}

$\mathrm{n}=$ Release Exponent, k-kinetic constant.

Table 5: $3^{2}$ full factorial design layout with result of responses

\begin{tabular}{ccccccc}
\hline \multirow{2}{*}{ Batch code } & \multicolumn{3}{c}{ Variables } & \multicolumn{5}{c}{ Response values } \\
\cline { 2 - 7 } & $\mathrm{X}_{1}$ & $\mathrm{X}_{2}$ & $\mathbf{R}_{1}$ (cps) & $\mathbf{R}_{\mathbf{2}}\left(\mathbf{N} / \mathrm{cm}^{2}\right)$ & $\mathbf{R}_{3}(\%)$ & $\mathbf{R}_{4}(\%)$ \\
\hline A & -1 & -1 & 3398 & 3.516092 & 28.08 & 99.76 \\
B & -1 & 0 & 5521 & 3.821839 & 17.22 & 90.29 \\
C & -1 & 1 & 9657 & 3.668966 & 17.67 & 92.75 \\
D & 0 & -1 & 17876 & 4.204023 & 16.76 & 66.65 \\
E & 0 & 0 & 28859 & 4.127586 & 13.58 & 63.58 \\
F & 0 & 1 & 39232 & 4.356897 & 15.35 & 71.74 \\
G & 1 & -1 & 28859 & 5.579885 & 7.69 & 42.49 \\
H & 1 & 0 & 31793.5 & 5.350575 & 7.34 & 39.38 \\
I & 1 & 1 & 56900 & 5.121264 & 7.99 & 46.12 \\
\hline
\end{tabular}

Where, R1: Viscosity of the Gel, R2: Mucoadhesive strength, R3: CPR at 1 hour and R4: CPR at 10 hour.

Table 6: Desirable values of responses

\begin{tabular}{ccc}
\hline Code & Responses & Desired value \\
\hline $\mathbf{R}_{1}$ & Viscosity of gel & $5000-7000 \mathrm{cps}$ \\
$\mathbf{R}_{2}$ & Mucoadhesive strength & $3.5-5.5 \mathrm{~N} / \mathrm{cm}^{2}$ \\
$\mathbf{R}_{3}$ & CPR at $1 \mathrm{hr}$ & $23-33 \%$ \\
$\mathbf{R}_{4}$ & CPR at $10 \mathrm{hr}$ & $81-91 \%$ \\
\hline
\end{tabular}

cross linking increased and release of drug from gel matrix decreased and as concentration of pectin increased it forms less viscous gel and hense increased release at the end of tenth hour.

\section{Validation of evolved model}

Checkpoint batches CP1 and CP2 were prepared at X1=-0.68 and -0.99 and X2 $=-0.77$ and -0.88 levels, respectively. The theoretical values of Viscosity and Mucoadhesive strength, CPR at 1 and $10 \mathrm{~h}$ of batches CP1 and CP2 were given in Table 4 . For the checkpoint batch CP1 the theoretical values were $6783.75 \mathrm{cps}, 3.69 \mathrm{~N} / \mathrm{m}^{2}, 25.84,92.53$ respectively. The experimental values are $6709.15 \mathrm{cps}, 3.74 \mathrm{~N} / \mathrm{m}^{2}, 27.17$ and 91.38 respectively (Table 4 ), which are in good agreement with theoretical values. Similarly, the experimental values of batch CP2 were also in good agreement with theoretical values.

\section{Selection of optimized batch using overlay plot}

Optimization of the formulation was done using Design expert software version 7.1.6. Target release kept for the optimization of the formulation was $23 \%$ to $33 \%$ drug release at the first hour, $81 \%$ to $91 \%$ at tenth hour, mucoadhesive strength 3.5 to $5.5 \mathrm{~N} / \mathrm{cm}^{2}$ and viscosity of gel 5000 to $7000 \mathrm{cps}$. Results showed that checkpoint Batch CP2 came closest to satisfying all the selection criteria.

From the factorial design study optimum values for dependent parameters were set for i.e., Viscosity $\left(R_{1}\right)$, Mucoadhesive strength $\left(R_{2}\right)$ and CPR at $1 \mathrm{~h}\left(\mathrm{R}_{3}\right)$ and $10 \mathrm{~h}\left(\mathrm{R}_{4}\right)$ respectively it was observed that batch CP2 could be formulated having composition (Table 6) of X1=-0.77 of Sodium alginate and $\mathrm{X} 2=0.88$ of Pectin which was found suitable in fulfilling all the desired characteristics as per the set parameter values or formulation criteria. Thus, Batch CP2 was prepared and evaluated further as an optimized batch.

\section{Evaluation of optimized batch}

The graph indicated good correlation coefficient 0.993 , so linearly water uptake was observed by the optimized batch CP2, so better diffusion and drug release observed from the gel formulations. The best fitted model was selected on the basis of relatively high $\mathrm{R}^{2}$ value. Optimized batch CP2 had diffusion exponent (n) value 0.534 indicated that the batch CP2 exhibited non-Fickian diffusion (Anomalous diffusion). Batch CP2 formulation can be best explained by the Higuchi model due to highest $\mathrm{R}^{2}$ value among all the models.

The formulation was evaluated for $\mathrm{pH}$, drug content uniformity and In-vitro drug release.The drug release kinetics of the optimized formulation followed Higuchi model which indicated that the drug release occurred by non-Fickian mechanism i.e. combination of both diffusion and erosion. The optimized batch CP2 was found clear, spreadable, exhibiting good drug content uniformity and showing no significant changes in viscosity, mucoadhesive strength and $\mathrm{pH}$ initially and after 30 days. All the parameters were within specifications. No significant changes were observed during stability period of 30 days.

\section{CONCLUSION}

It can be concluded that the drug release from the In-situ oral gel formulation can be modulated by the use of different amount of gel forming polymers.From the results, batch CP2 was reported as optimized batch. In this batch, $0.346 \% \mathrm{w} / \mathrm{v}$ Sodium Alginate and $0.324 \% \mathrm{w} / \mathrm{v}$ Pectin were reported as optimized concentration. Release kinetic study showed that the diffusion mechanism is anomalous and model which was followed 
by Higuchi model.Thus, In-situ gelling system of Cefuroxime Axetil was successfully developed by ionic cross linking method that could form gel instantaneously when in contact with gastric fluid and remains in stomach for more than $12 \mathrm{~h}$.

\section{ACKNOWLEDGEMENT}

The Authors are highly thankful to the Comed Pharmaceuticals ltd., Baroda, CP Kelco, Mumbai, Colorcon, Goa for providing the drug sample and other excipients for the research work.

\section{CONFLICTS OF INTEREST}

Conflicts of interest declared none.

\section{ABBREVIATIONS USED}

CPR: Cumulative Percentage Drug Release; FTIR: Fourier Transform Infra-Red Spectroscopy; RPM: Revolutions Per Minute; HCI: Hydrochloride; UV: Ultra Violet Spectroscopy; nm: Nanometer; cps: Centipoise; HPMC: Hydroxy Propyl Methyl Cellulose.

\section{ABOUT AUTHORS}

Dr. Divyesh H. Shastri: Dr. Hitesh Dodiya and Dr. Pragna K Shelat are Faculties in the Department of Pharmaceutics, K. B. Institute of Pharmaceutical Education \& Research, Gandhinagar, affiliated to Kadi Sarva Vishwavidyalaya.

Mr. Alkesh Bhanupriy: Is working as Research Scientist, F \& D at Claris Otsuka, Ahmedabad, Gujarat.

\section{REFERENCES}

1. Nighute AB, Bhise SB. Preparation and Evaluation of Microcrystals of Cefuroxime Axetil. Int J PharmTech Res. 2009;1(3):424-30.

2. Beringer P. Remington: The Science And Practice of Pharmacy: Lippincott Williams \& Wilkins; 2005.

3. Li LC, Tian YE. Encyclopedia of Pharmaceutical Technology; James S; James CB. eds. Marcel Dekker Inc. NY: 2002.

4. Wise DL. Handbook of Pharmaceutical Controlled Release Technology: Marcel Dekker Inc. NY: 2000.

5. Robinson JR, Lee VHL. Con. Drug Del. Fundamentals and Applications: Marcel Dekker Inc. NY:1987.

6. Banker GSand Rhodes CT. Modern Pharmaceutics: Marcel Dekker Inc. NY:2002

7. Hoffman A, Stepensky D, Lavy E, Eyal S, Klausner E, Friedman M. Pharmacokinetic and pharmacodynamic aspects of gastroretentive dosage forms. Int J Pharm. 2004;277(1-2):141-53.

8. Bardonnet PL, Faivre V, Pugh WJ, Piffaretti JC and Falson F. Gastroretentive dosage forms: Overview and special case of Helicobacter pylori. J Con Rel. 2006;111(1-2):1-18

9. Andrews GP, Laverty TP and Jones DS. Mucoadhesive polymeric platforms for controlled drug delivery. Eur J Pharm Biopharm. 2009;71(3):505-18.

10. Singh BN, Kim KH. Floating drug delivery systems: an approach to ora controlled drug delivery via gastric retention. J Con Rel. 2000;63(3):235-59.

11. Khar V. Targeted \& Controlled Drug Delivery: Novel Carrier Systems (HB): CBS Publishers \& Distributors; 2006

12. Talukder R and Fassihi R. Gastroretentive delivery systems: a mini review. Drug Dev Ind Pharm. 2004;30(10):1019-28.

13. Garg R, Gupta G. Progress in controlled gastroretentive delivery systems. Tro J Pharm Res. 2008;7(3):1055-66.

14. Dave BS, Amin AF and Patel MM. Gastroretentive drug delivery system of ranitidine hydrochloride: formulation and in-vitro evaluation. AAPS Pharm Sci Tech. 2004;5(2):77-82

15. Gopalakrishnan S, Chenthilnathan A. Floating Drug Delivery Systems: A Review. J Pharm SciTech. 2011:3(2):548-54.

16. Chawla $G$ and Bansal $A$. A means to address regional variability in intestinal drug absorption. Pharm Tech. 2003;27(2):50-68.

17. Mojaverian $\mathrm{P}$, Vlasses $\mathrm{PH}$, Kellner PE and Rocci ML. Effects of gender, posture and age on gastric residence time of an indigestible solid: pharmaceutical considerations. Pharm Res. 1988;5(10):639-44.

18. Huggi M. Formulation and evaluation of gastroretantive mucoadhesive tablets of cefuroxime axetil. 2011

19. Gandhi RB and Robinson JR. Oral cavity as a site for bioadhesive drug delivery. Adv Drug Del Rev. 1994;13(1-2):43-74.

20. Rajinikanth PS and Mishra B. Floating in situ gelling system for stomach site- specific delivery of clarithromycin to eradicate H. pylori. J Con Rel. 2008 125(1):33-41.

21. Ganguly S, Dash AK. A novel insitu gel for sustained drug delivery and targeting Int J Pharm. 2004;276(1-2):83-92.

22. Ruel-Gariépy E and Leroux JC. In-situ-forming hydrogels-review of temperaturesensitive systems. Eur J Pharm Biopharm. 2004;58(2):409-26.

23. Srividya B, Cardoza RM and Amin P. Sustained ophthalmic delivery of ofloxacin from a pH triggered in situ gelling system. J Con Rel. 2001;73(2):205-11.

24. Cohen S, Lobel E, Trevgoda A, Peled Y. A novel in situ-forming ophthalmic drug delivery system from alginates undergoing gelation in the eye. J Con Rel. 1997;44(2-3):201-8.

25. Chen T, Small DA, McDermott MK, Bentley WE and Payne GF. Enzymatic methods for in situ cell entrapment and cell release. Biomacromol. 2003;4(6):1558-63.

26. Gupta P, Trenor SR, Timothy E and Wilkes GL. In situ photo-cross-linking of cinnamate functionalized poly (methyl methacrylate-co-2-hydroxyethyl acrylate) fibers during electrospinning. Macromol. 2004;37(24):9211-8.

27. Miyazaki S, Kubo W and Attwood D. Oral sustained delivery of theophylline using In-situ gelation of sodium alginate. J Con Rel. 2000;67(2-3):275-80.

28. Kubo W, Miyazaki S and Attwood D. Oral sustained delivery of paracetamo from in situ-gelling gellan and sodium alginate formulations. Int J Pharm 2003;258(1-2):55-64.

29. Miyazaki S, Suzuki S, Kawasaki N, Endo K, Takahashi A and Attwood D. In situ gelling xyloglucan formulations for sustained release ocular delivery of pilocarpine hydrochloride. Int J Pharm. 2001;229(1-2):29-36.

30. Gratieri T, Gelfuso GM, Rocha EM, Sarmento VH and Lopez RFV. A poloxamer/ chitosan in situ forming gel with prolonged retention time for ocular delivery. Eur J Pharm Biopharm. 2010;75(2):186-93

31. Shastri D and Patel L. Optimization of polyox based thermoreversible mucoadhesive ophthalmic In-situ hydrogel using 32 full factorial design. Inventi Impact: Pharm Tech. 2010

32. Shastri DH, Prajapati ST and Patel LD. Thermoreversible mucoadhesive ophthalmic in situ hydrogel: Design and optimization using a combination of polymers. Acta Pharm. 2010;60(3):349-60

33. Shelke S, Dongre S, Rathi A, Dhamecha D, Maria S and Dehghan MHG. Development and Validation of UV Spectrophotometric Method of Cefuroxime Axeti in Bulk and Pharmaceutical Formulation. Asian J Res Chem. 2009:2(2):222-4.

34. Health IMO and Welfare F. Indian Pharmacopoeia, 1996: Veterinary supplement 2000: Controller of Publications; 2000.

35. R P and A B. Formulation Evaluation and Optimization of stomach specific In situ gel of Ranitidine Hydrochloride. Int J Pharm Sci Nanotech. 2010;3(1):834-42.

36. B T. Design and evaluation of floating In-situgelling system of clarithromycin for treatment of Helicobacter Pylori Infection. Gandhinagar: Kadi Serva Vishwavidhyalaya; 2010. 